“C 2017 IEEE. Personal use of this material is permitted. Permission from IEEE must be obtained for all other uses, in any current or future media, including reprinting/republishing this material for advertising or promotional purposes, creating new collective works, for resale or redistribution to servers or lists, or reuse of any copyrighted component of this work in other works." 


\title{
Implementation of a Motor Control System for Electric Bus based on DSP
}

\author{
Xiaojin Men ${ }^{1,2 *}$, Youguang $\mathrm{Guo}^{2}$, Gang $\mathrm{Wu}^{1}$ and Jianguo $\mathrm{Zhu}^{2}$ \\ ${ }^{1}$ Department of Automation, University of Science and Technology of China, Hefei, Anhui, China \\ ${ }^{2}$ Faculty of Engineering and Information Technology, University of Technology Sydney, NSW 2007, Australia \\ Email: xjmen@mail.ustc.edu.cn
}

\begin{abstract}
Motor control system may be the most important part of electric vehicles. To implement the control strategies, a lot of practical problems need to be taken into account. In this paper, an induction motor control system for electric bus is developed based on digital signal processing (DSP). The control strategy is based on field-oriented control and space vector pulse width modulation. Over-modulation, field weakening control, PI controller and fault diagnosis are also applied in this DSP algorithm. As a practical product running on a real electric bus with an $100 \mathrm{~kW}$ induction motor, communication with vehicle control unit (VCU) by Controller Area Network (CAN bus), control system safety and PC software designed for experiment at lab are also discussed. The transient and steady-state performances of this motor control system are analyzed by experiments. Its performance is satisfactory when applied to the real electric bus.

Index Terms-DSP, Electric vehicle, Field oriented control, Induction motor.
\end{abstract}

\section{INTRODUCTION}

Recently, electric vehicle has been promoted as a practical platform for mitigating energy crisis and reducing environmental pollution. Motor control system, vehicle control unit (VCU) and battery management system (BMS) are the main control systems of electric vehicles. Other technologies of electric vehicle include the motor design, battery design, body and chassis design, and particularly the system-level design and optimization of electric motor drive systems [1]-[3].

Motor control system plays a very important role in driver comfort and safety. Induction motors (IMs) are widely used for electric vehicles due to their good performance, simple structure and low cost [4]-[6]. As for the control methods for IM, there are the V/F control, field oriented control (FOC), direct torque control (DTC) and some modern control methods, like model predictive control (MPC), fuzzy control, and neural networks. However, for commercial products of electric vehicles, FOC appears to be the most popular control strategy [7], [8].

This paper is focused on how to implement the induction motor control system for electric bus based on DSP. Besides the implementation of FOC and space vector pulse width modulation (SVPWM), some practical problems, such as current protection, over-modulation and field weakening control method are all discussed and the performance of final control strategy is verified on a real electric bus. This paper shows some aspects, which need to be taken into account when implementing motor control methods on digital control chips, like DSP, for industrial application. It will do some help for applying new control methods like MPC on industrial motor to achieve better performance..

\section{Construction OF System}

\section{A. Model of IM}

A mathematical machine model of an IM described in the stationary frame is expressed as:

$$
\begin{aligned}
u_{s} & =R_{s} i_{s}+\frac{d \psi_{s}}{d t} \\
u_{r} & =R_{r} i_{r}+\frac{d \psi_{r}}{d t}-j \omega_{r} \psi_{r} \\
\psi_{s} & =L_{s} i_{s}+L_{m} i_{r} \\
\psi_{r} & =L_{m} i_{s}+L_{r} i_{r} \\
T_{e} & =\frac{3}{2} p \delta L_{m}\left(\psi_{r} \otimes \psi_{s}\right)
\end{aligned}
$$

where $u_{s}, i_{s}, u_{r}, i_{r}, \psi_{s}$ and $\psi_{r}$ are the stator voltage vector, stator current vector, rotor voltage vector, rotor current vector, stator flux linkage vector and rotor flux linkage vector, respectively; $R_{s}, R_{r}, L_{s}, L_{r}$ and $L_{m}$ are the stator resistance, rotor resistance, stator inductance, rotor inductance and mutual inductance, respectively; $\omega_{r}$ is the electrical rotor speed, $p$ is the number of pole pairs and $\delta=1 /\left(L_{s} L_{r}-L_{m}^{2}\right)[9]$.

The mathematical machine model of an IM expressed in the rotating coordinates frame is:

$$
\begin{gathered}
\psi_{r d}=\frac{L_{m}}{\tau_{r} s+1} i_{s d} \\
T_{e}=\frac{3}{2} \frac{L_{m}}{L_{r}} p \psi_{r d} i_{s q}
\end{gathered}
$$

where $\tau_{r}=\frac{L_{r}}{R_{r}}$ is the time constant of the rotor, and $i_{s d}$ and $i_{s q}$ are the two orthogonal components of the stator current, respectively.

Since the variables are expressed in a rotating coordinates frame, the electromagnetic torque can be controlled via the imaginary component of the stator current $i_{s q}$ and the rotor flux magnitude $\psi_{r d}$ is controlled by its real part $i_{s d}[10]$.

\section{B. Construction of Motor Control System}

Fig. 1 shows the diagram of the motor control system. The motor control system of electric bus includes the power supply module, DSP controller, protection and adjustment module, IGBT driver and resolver to digital convertor. The power source of electric bus is a $650 \mathrm{~V}$ battery set. It supplies voltage to IGBT driver and converts to different voltage power source as required for other parts 


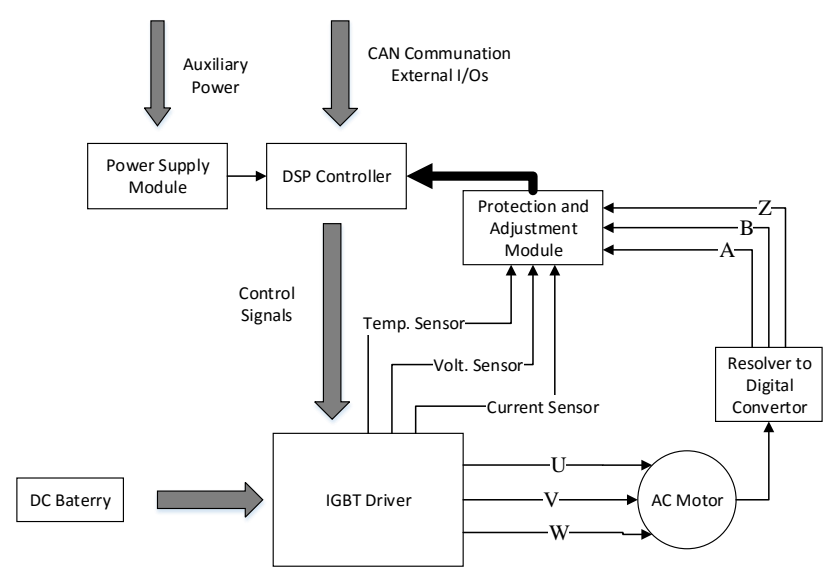

Fig. 1. Diagram of motor control system.

of motor control system. IGBT module receives instructions from DSP controller and produces three phase voltage (UVW) to drive the induction motor. It also collects the temperature, voltage and current signals and then transfers them to the DSP controller via protection and adjustment module. Resolver to digital convertor detects the motor speed and direction and then produces three corresponding signals (ABZ) and transfers them to DSP for speed calculation. Signals A and B are two square wave signals with 90 electrical degrees out of phase, which contain the data of motor speed. Signal $\mathrm{Z}$ is the signal of direction. DSP controller communicates with vehicle controller by CAN bus. It produces the motor drive PWM signals based on FOC and SVPWM algorithm and sends them to IGBT driver and thus drives motors. The DSP TMS320F28335 is used in the experiments and real bus motor control system. It is a 32-bit floating-point processor, which is produced by Texas Instruments (TI). Its high performance is quite appropriate for motor control system [11].

\section{IMPLEMENTATION OF FOC}

\section{A. Scheme of FOC for AC IM}

Fig. 2 is the basic scheme of FOC for AC IM. Some function blocks are designed by using some modules from TI library. These function blocks are easy to update and comfortable to add new functions, which make them portable to use in other systems as well. Each macro function block has its parameters, input and output. When running the algorithm on DSP, these blocks are tested level by level [12]. The results are checked at each level to ensure that all these functions are running well as required.

IPARK MACRO is the inverse Park transformation and PARK MACRO is the Park transformation. CLARK MACRO is the Clark transformation. SVGEN MACRO includes inverse Clark transformation and SVPWM. There are six basic vectors $\left(\mathrm{U}_{1}-\mathrm{U}_{6}\right)$ and two zero vectors $\left(\mathrm{U}_{0}, \mathrm{U}_{7}\right)$ in the three-phase inverter as shown in Fig. 3.

Giving $U_{\alpha}$ and $U_{\beta}$, one can have a $U_{\text {ref }}$ as input, which can be equally obtained from two of the six basic vectors. In the DSP program, it is needed to acquire the PWM durations T1 and T2 of the two corresponding basic vectors. Therefore, one has to know in which sector the
$U_{\text {ref }}$ is located for acquiring the correct duration. To find out the correct sector, three variables, $V_{\text {ref } 1}, V_{\text {ref } 2}, V_{\text {ref } 3}$ are used.

$$
\begin{gathered}
V_{\text {ref } 1}=U_{\beta} \\
V_{\text {ref } 2}=\frac{-U_{\beta}+\sqrt{3} U_{\alpha}}{2} \\
V_{\text {ref } 3}=\frac{-U_{\beta}-\sqrt{3} U_{\alpha}}{2}
\end{gathered}
$$

If $V_{\text {ref } 1}>0$ then a=1, else $\mathrm{a}=0$;

If $V_{\text {ref } 2}>0$ then $\mathrm{b}=1$, else $\mathrm{b}=0$;

If $V_{\text {ref } 3}>0$ then $\mathrm{c}=1$, else $\mathrm{c}=0$;

The sector is defined as, sector $=4 * \mathrm{c}+2 * \mathrm{~b}+\mathrm{a}$. According to this, the correct sector, in which the $U_{\text {ref }}$ is located, can be worked out. As to the duration, it can be found that there are only three basic values for calculating all the possible occasions. Use variables $\mathrm{X}, \mathrm{Y}, \mathrm{Z}$ to calculate the final duration, where

$$
\begin{aligned}
& \mathrm{X}=U_{\beta} \\
& \mathrm{Y}=\frac{1}{2}\left(\sqrt{3} U_{\alpha}+U_{\beta}\right) \\
& \mathrm{Z}=\frac{1}{2}\left(-\sqrt{3} U_{\alpha}+U_{\beta}\right)
\end{aligned}
$$

Then the duration table can be obtained as table I shown below. As implementation is based on DSP, we should use the related registers to get the trigger value and thus we can get the expected PWM for motor drive [7].

QEP MACRO and SPEED FR MACRO is the part of calculation of motor speed. CURMOD MACRO is the current module. It uses the motor speed to calculate the electrical angle, which is needed for Park transformation and inverse Park transformation. PID MACRO is the PID control unit, which plays a great role in the transient and steady-state performance of the control system.

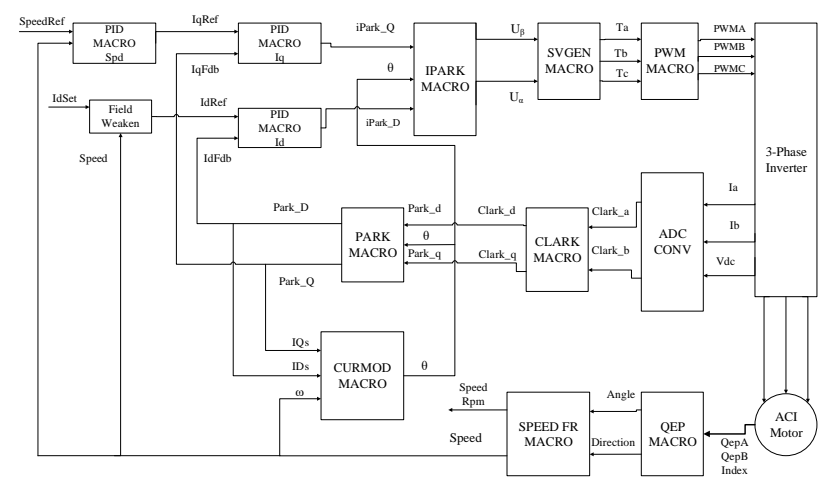

Fig. 2. Scheme of FOC based on DSP. 


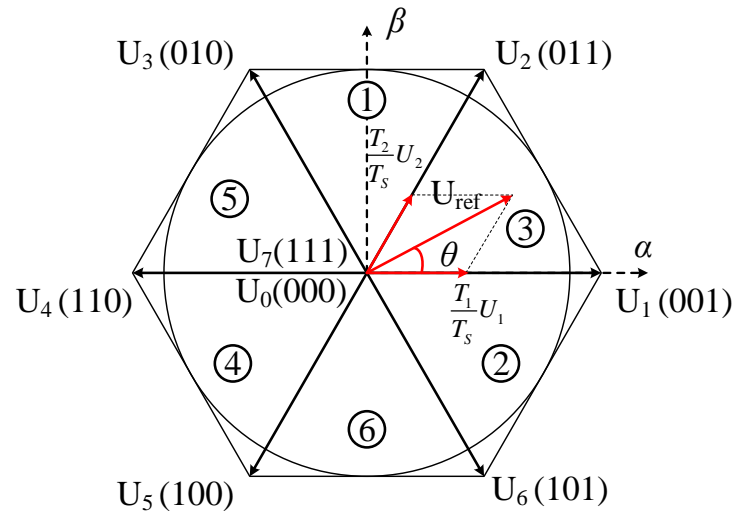

Fig. 3. SVPWM scheme: $U_{1}-U_{6}$ are the basic vectors, $U_{0}$ and $U_{7}$ are the zero vectors, and $\mathrm{T}_{\mathrm{s}}$ is the control period.

TABLE I

DURATION SELECT TABLE

\begin{tabular}{|c|c|c|c|c|c|c|}
\hline Sector & 3 & 1 & 5 & 4 & 6 & 2 \\
\hline $\begin{array}{c}\text { Vecto } \\
\mathrm{r}\end{array}$ & $\mathrm{U}_{1}$, & $\mathrm{U}_{3}$, & $\mathrm{U}_{3}$, & $\mathrm{U}_{5}$, & $\mathrm{U}_{5}$, & $\mathrm{U}_{1}$, \\
$\mathrm{U}_{2}$ & $\mathrm{U}_{4}$ & $\mathrm{U}_{4}$ & $\mathrm{U}_{6}$ & $\mathrm{U}_{6}$ \\
\hline $\mathrm{t} 1$ & $-\mathrm{Z}$ & $\mathrm{Z}$ & $\mathrm{X}$ & $-\mathrm{X}$ & $-\mathrm{Y}$ & $\mathrm{Y}$ \\
\hline $\mathrm{t} 2$ & $\mathrm{X}$ & $\mathrm{Y}$ & $-\mathrm{Y}$ & $\mathrm{Z}$ & $-\mathrm{Z}$ & $-\mathrm{X}$ \\
\hline
\end{tabular}

\section{B. DSP Algorithm}

The FOC is implemented on DSP and it is part of the motor control system for electric bus. Its control frequency is actually based on the PWM interrupt service frequency. Besides the main FOC algorithm, the system protection, error detection, over-modulation, field weakening, communication with PC and vehicle control unit and other aspects, are also considered.

The main program flow diagram is shown in Fig. 4. When the motor control system starts, the system clock and GPIO are initialized by function DeviceInit(). MemCopy() moves MainISR to RAM from flash to save running time. GetSysPara() is the function of reading parameters from FRAM. These parameters include the motor parameters and some parameters for communication between DSP and PC. Three tasks are running in the background loop. The FOC control algorithm runs in PWM interruption service function program (PWM_ISR) and FAULT_ISR deals with all the error detection work. When the system detects some errors in running state, the protection action will be triggered and the motor speed will decelerate gradually and the motor will shut down in the end. Errors will be uploaded to the Vehicle Control Unit or PC for analysis.

The MAINISR program flow diagram is shown in Fig. 5. The modules mentioned in the FOC scheme are used in this program. PWM signals are produced as required by these program.

As this implementation is based on DSP and used for electric bus, some work about electric bus also needs to be accomplished. Three tasks in background loop are used to deal with these problems. AD sampling, temperature and battery voltage monitor, current protection and collecting data for analysis are running in task A. Communications with vehicle control unit and $\mathrm{PC}$ are operating in task $\mathrm{B}$ and task C. The CAN module of DSP is used to perform this communication. When transferring data by CAN, the protocol with each terminal equipment needs to be made. The driver's instructions, like starting moving, stopping moving, accelerating the speed, and changing gears, are all sent by CAN in these tasks.

\section{Practical Problems}

The motor control system designed is for real electric bus, some practical problems of implementation need to be considered.

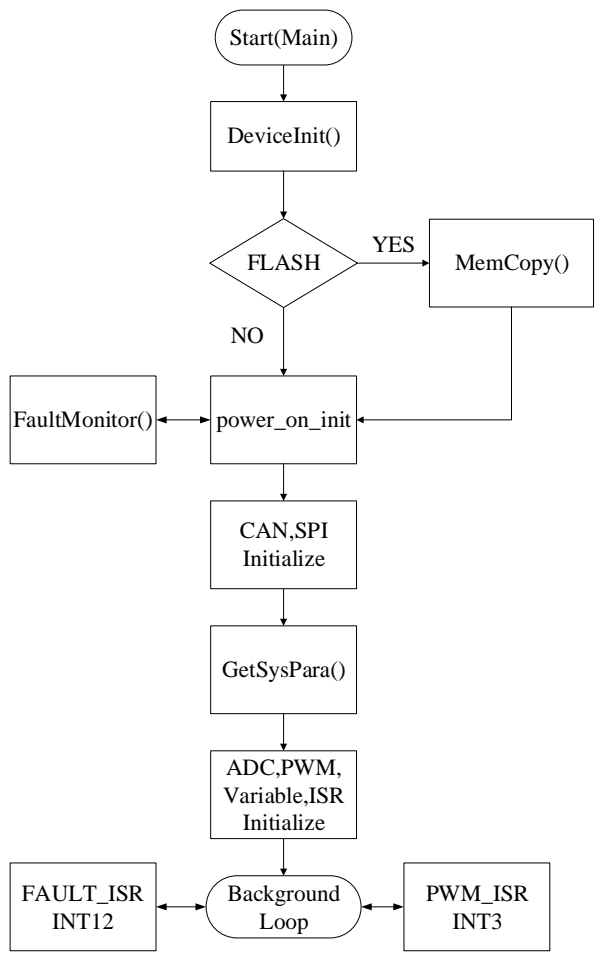

Fig. 4. Main DSP program flow diagram.
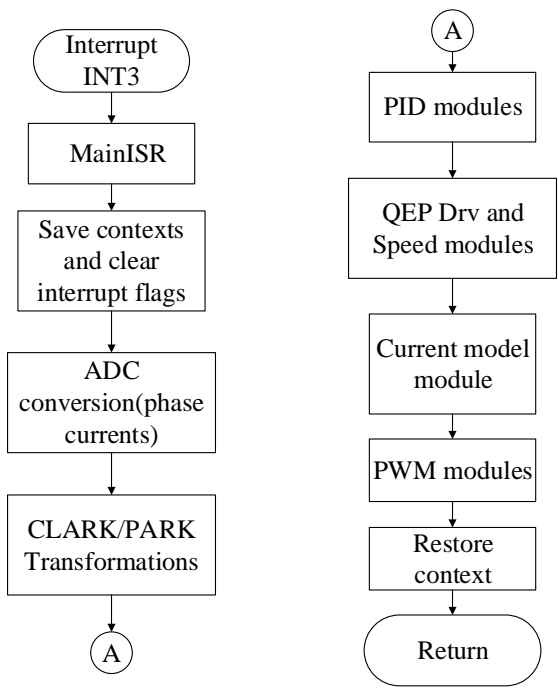

Fig. 5. PWMISR program flow diagram. 


\section{A. Initial Excitation Current}

According to (6), the flux is dependent on $\mathrm{I}_{\mathrm{sd}}$ and torque is related to $I_{s q}$. For convenience, $I_{d}$ presents $I_{s d}$ and $I_{q}$ presents $\mathrm{I}_{\mathrm{sq}}$ in the flowing part for implementing on electric bus. The driver's acceleration paddle is related to $I_{q} . I_{d}$ is not controlled by the driver and thus it should be set up as initial value in the program. The no-load current is $I_{0}$, which is a constant of the motor. Therefore, it is requested to decide the correct $\mathrm{I}_{\mathrm{d}}$ from $\mathrm{I}_{0}$.

The inverse Park transformation is:

$$
\left[\begin{array}{l}
I_{\alpha} \\
I_{\beta}
\end{array}\right]=\left[\begin{array}{cc}
\cos \theta & -\sin \theta \\
\sin \theta & \cos \theta
\end{array}\right]\left[\begin{array}{l}
I_{d} \\
I_{q}
\end{array}\right]
$$

where $I_{\alpha}, I_{\beta}$ are the currents in stationary coordinates frame and $I_{d}, I_{q}$ are the currents in rotating coordinates frame, and $\theta$ is the electrical angle, respectively.

Set $I_{q}=0$, one can have

$$
\begin{aligned}
& I_{\alpha}=\cos \theta * I_{d} \\
& I_{\beta}=\sin \theta * I_{d}
\end{aligned}
$$

The Clark transformation is:

$$
\left[\begin{array}{l}
\mathrm{I}_{a} \\
I_{b} \\
I_{c}
\end{array}\right]=\left[\begin{array}{cc}
1 & 0 \\
-\frac{1}{2} & \frac{\sqrt{3}}{2} \\
-\frac{1}{2} & -\frac{\sqrt{3}}{2}
\end{array}\right]\left[\begin{array}{l}
I_{\alpha} \\
I_{\beta}
\end{array}\right]
$$

where $I_{a}, I_{b}, I_{c}$ are the currents in the three phase frame. Combining (17) with (15) and (16), one can have

$$
\begin{aligned}
& I_{\mathrm{a}}=\cos \theta * I_{d} \\
& I_{\mathrm{b}}=\cos \left(\theta-120^{\circ}\right) * I_{d} \\
& I_{\mathrm{c}}=\cos \left(\theta+120^{\circ}\right) * I_{d}
\end{aligned}
$$

The RMS current of $I_{\mathrm{a}}$ equals $I_{d} / \sqrt{2}$, and thus

$$
I_{d}=\sqrt{2} I_{0}
$$

According to (21), the correct excitation current can be confirmed for the system based on motor parameter.

\section{B. Consistency of Current of Program and Motor}

In the DSP program, the three phase currents of motor, $I_{a}, I_{b}$ and $I_{c}$, can be used and the program produces duration of PWM to control the current. The motor has three phases, namely, $\mathrm{U}, \mathrm{V}$ and $\mathrm{W}$. When producing the PWM duration, the correct basic vector is used, which is directly related to the three physical bridges of IGBT. The phase current data are obtained by AD converter. The correct corresponding feedback current is needed to calculate the error as input of PID controller.

(1) Set $I_{d}=1$, and $I_{q}=0$, which means that the voltage vector is $U_{1}(001)$. Check the motor's three phase output, UVW. The phase with longer time of high level means that it is the feedback of $I_{a}$ in the program.

(2) Set $I_{d}=0$, and $I_{q}=1$, which means that the voltage vector is combination of $\mathrm{U}_{3}(010)$ and $\mathrm{U}_{2}(011)$. Check the output of UVW. The phase with longest time of high level means the feedback of $I_{b}$ and that with the shortest time of high level means the feedback of $I_{c}$.

According to these experiments, Ia, Ib, and Ic in the program can match with the physical motor phases $\mathrm{U}, \mathrm{V}$, and $\mathrm{W}$. If they do not match, the performance of torque and speed would be very bad.

\section{Over Modulation}

When the values of $I_{d}$ and $I_{q}$ are given, the $U_{\text {ref }}$ is settled as well. According to the principle of SVPWM, the duration of PWM as T1 and T2 can be obtained. However, improper $\mathrm{U}_{\text {ref }}$ could lead to the sum of $\mathrm{T} 1$ and $\mathrm{T} 2$ of more than unit 1 . In the program, the unit 1 is settled by control period. Therefore, when T1 or T2 is not correct, the distortion of current and low power efficiency may happen. To avoid this situation, an easy but proper way is chosen. That is to scale down $\mathrm{T} 1$ and $\mathrm{T} 2$ to make their sum equal to unit 1. The logic diagram is shown in Fig 6

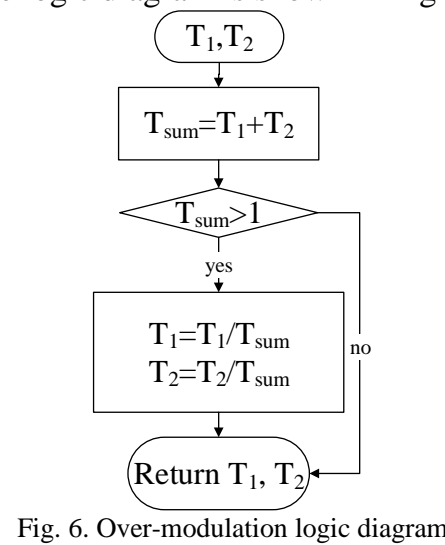

\section{Field Weakening Control Strategy}

The system power will reach its rated value when the motor reaches its rated speed. To achieve higher speed, the excitation current needs to be reduced. In this project, a variable $x_{m}$ is used to weaken the flux. It can be written as the form below

$$
x_{m}=f\left(v^{-1}, v^{-2}\right)
$$

\section{EXPERIMENTAL RESULTS AND DISCUSSIONS}

Fig. 7 shows the experiment setup, with the voltage source, target induction motor, current sensors, oscilloscope, dynamometer, etc. The parameters of target motor is listed in Table II.

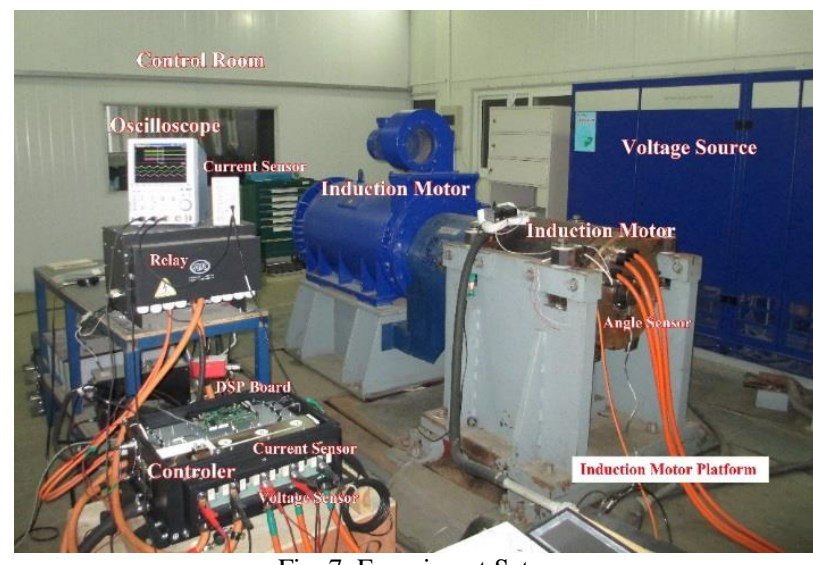

Fig. 7. Experiment Setup

TABLE II

MOTOR PARAMETERS

\begin{tabular}{|c|c|c|}
\hline \multicolumn{3}{|c|}{ MOTOR PARAMETERS } \\
\hline Motor Parameters & Value & Unit \\
\hline Rated power & 100 & $\mathrm{~kW}$ \\
\hline
\end{tabular}




\begin{tabular}{|c|c|c|}
\hline Rated voltage & 350 & V \\
\hline Rated current & 178 & $\mathrm{~A}$ \\
\hline Rated speed & 980 & $\mathrm{rpm}$ \\
\hline Number of pole pairs & 3 & \\
\hline $\mathrm{Rr}$ & 0.01 & $\Omega$ \\
\hline $\mathrm{Lr}$ & 7.5 & $\mathrm{mH}$ \\
\hline $\mathrm{Rs}$ & 0.019 & $\Omega$ \\
\hline Ls & 10.9 & $\mathrm{mH}$ \\
\hline Peak power & 250 & $\mathrm{~kW}$ \\
\hline Max torque & 2400 & $\mathrm{Nm}$ \\
\hline
\end{tabular}

The experiment is carried out on a two towing motor test bench. When the experiments are conducted for testing speed, the opposite motor will offer a fix torque. When the experiments are conducted for torque, the opposite motor will offer a fix speed. By doing these, the transient performance and steady state performance can be achieved.

When the driver of electric bus gives an acceleration signal, it will be finally transformed to an $I_{q}$ value by the control system and then carried out to obtain a demanded torque and the speed of bus increases as a consequence. For experiment at lab, the motor control system can be connected with PC and the instruction is given by software in PC. The load motor can be set to run at a fix speed and then different $I_{q}$ is set to acquire the torque performance of target motor. The responses of torque regarding to different input values of $I_{q}$, is shown in Fig. 8 and the torque ripple of rated value $(1000 \mathrm{Nm})$ is shown in Fig. 9. In Fig. 8, Iq is increased step by step, while the speed is fixed by the opposite motor as a load. The transient response is satisfactory and its torque is very stable with a ripple of under $\pm 5 \%$, which is normally considered as a good performance for electric bus.

\section{CONCLUSIONS}

This paper introduces an implementation of motor control system for electric bus with an $100 \mathrm{~kW}$ induction motor based on DSP F28335. Some problems of implementation as industrial product are put forward and some corresponding solutions are also proposed. Its performance is verified by experimental results, which are satisfactory.

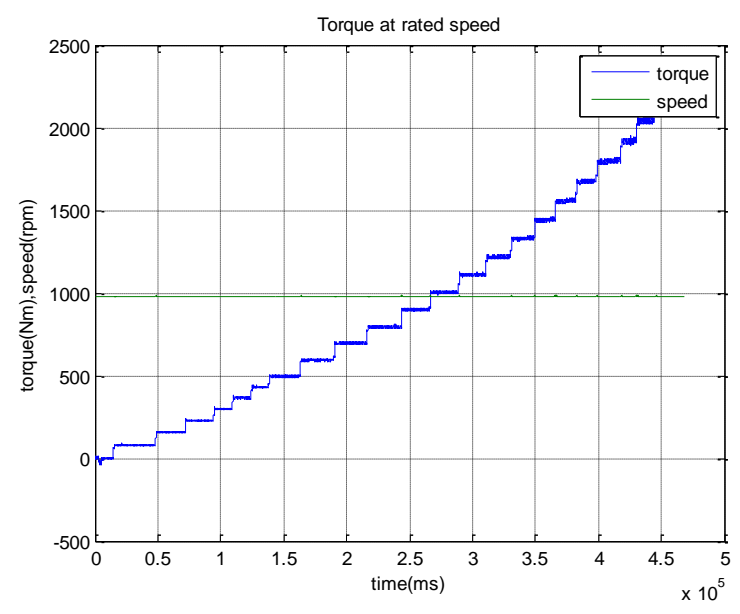

Fig. 8. Torque responses versus changing Iq

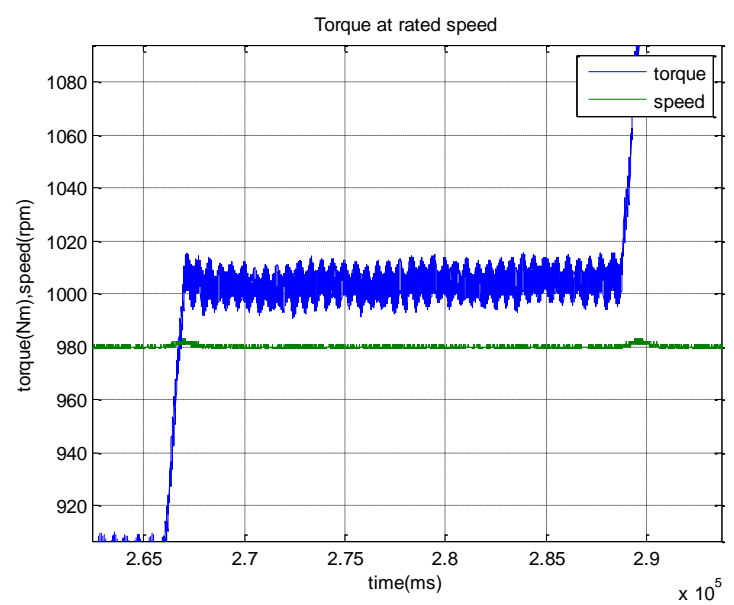

Fig. 9. Ripples at rated torque.

\section{REFERENCES}

[1] W. Xu, J. G. Zhu, Y. G. Guo, S. H. Wang, Y. Wang, and Z. Shi, "Survey on drive machines in electrical cehicles," in Proc. Int. Conf. on Applied Superconductivity and Electromagnetic Devices, 2009, pp. 167-170.

[2] G. Lei, T. S. Wang, Y. G. Guo, J. G. Zhu, and S. H. Wang, "System-level design optimization methods for electrical drive systems-robust approach," IEEE Transactions on Industrial Electronics, vol. 62, no. 8, pp. 4702-4713, Aug. 2015.

[3] G. Lei, T. S. Wang, Y. G. Guo, J. G. Zhu, and S. H. Wang, "System-level design optimization methods for electrical drive systems: deterministic approach," IEEE Transactions on Industrial Electronics, vol. 61, no. 12, pp. 6591-6602, Dec. 2014.

[4] W. Xu, J. G. Zhu, L. Tan, Y. G. Guo, S. H. Wang, and Y. Wang, "Optimal design of a linear induction motor applied in transportation," in Proc. Int. Conf. on Industrial Technology, 2009, pp. 790-795.

[5] Y. G. Guo, W. Xu, J. G. Zhu, H. Y. Lu, and J. X. Jin, "Design and analysis of a linear induction motor drive for a prototype HTS maglev transportation system," in Proc. Int. Conf. on Applied Superconductivity and Electromagnetic Devices, 2009, pp. 81-84.

[6] W. Xu, J. G. Zhu, Y. Zhang, Y. Li, Y. Wang, and Y. G. Guo, "An improved equivalent circuit model of a single-sided linear induction motor," IEEE Transactions on Vehicle Technology, vol. 59, no. 5, pp. 2277-2289, 2010. 
[7] D. Casadei, F. Profumo, G. Serra, and A. Tani, "FOC and DTC: Two viable schemes for induction motors torque control," IEEE Transactions on Power Electronics, vol. 17, no. 5, pp. 779-787, 2002.

[8] B. K. Bose, M. G. Simoes, D. R. Crecelius, K. Rajashekara, and R. Martin, "Speed sensorless hybrid vector controlled induction motor drive," in Conf. Rec. IEEE-IAS Annu. Mtg., 1995, pp. 137-143.

[9] Y. Zhang, H. Yang, and Z. Li, "A simple SVM-based deadbeat direct torque control of induction motor drives," in Proc. Int. Conf. Electrical Machines and Systems 2013, pp. 2201-2206.

[10] J. Rodriguez and P. Cortes, Predictive Control of Power Converters and Electrical Drives, John Wiley \& Sons, 2012.

[11] Instruments T. TMS320F28335, Digital Signal Controllers (DSCs), Data Manual, Literature Number: SPRS439I, 2007.

[12] B. Akin and M. Bhardwaj, "Sensored field oriented control of 3-phase induction motors," Texas Instrument Guide, 2013.

[13] Instruments, Texas, TMS320x2833x, 2823x enhanced pulse width modulator (ePWM) module reference guide (literature number: SPRUG04A). 2009. 